\title{
Obesity and Risk of Comorbidity: Prevalence and Associated Factors in Children Aged 6 to 9 Years in Public and Private Schools in Douala-Cameroon
}

\author{
Ayina Ayina Clarisse Noel ${ }^{1,2, *}$, Assomo Ndemba Peguy Brice ${ }^{2,3}$, Mekoulou Ndongo Jerson ${ }^{1,2}$, \\ Bilog Nadine Carole ${ }^{2}$, Ahmadou ${ }^{1}$, Bindi Ngasse Josiane Gertrude ${ }^{2}$, Etaga Noel Babayana ${ }^{2}$, \\ Temfemo Abdou ${ }^{2,4}$, Mbanya Jean Claude ${ }^{5}$, Sobngwi Eugène ${ }^{5}$, Mandengue Samuel Honoré ${ }^{1,2}$, \\ Etoundi Ngoa Laurent Serge ${ }^{3,6}$ \\ ${ }^{1}$ Department of Animal and Biology, Faculty of Science, University of Douala, Douala, Cameroun \\ ${ }^{2}$ Exercise and Sport Physiology Unit, Faculty of Science, University of Douala, Douala, Cameroon \\ ${ }^{3}$ Department of Physiology, Faculty of Medicine and Biomedical Sciences, University of Yaounde I, Yaounde, Cameroon \\ ${ }^{4}$ Department of Medicine, Faculty of Medicine and Pharmaceutical Sciences, University of Douala, Douala, Cameroon \\ ${ }^{5}$ Department of Internal Medicine and Specialties, Faculty of Medicine and Biomedical Science, University of Yaoundé I, Yaoundé, \\ Cameroon \\ ${ }^{6}$ Department of Animal Science, Higher Teacher's Training College, University of Yaoundé I, Yaounde, Cameroon
}

\section{Email address:}

c_ayina@yahoo.fr (A. A. C. Noel), assomo_ndemba@yahoo.fr (A. N. P. Brice), meckjerson@yahoo.fr (M. N. Jerson), billycarolle10@yahoo.fr (B. N. Carole), gahmadou@yahoo.fr (Ahmadou), trudyren3101@gmail.com (B. N. J. Gertrude), etaganoel@yahoo.fr (E. N. Babayana), temfemo@hotmail.com (T. Abdou), jcmbanya@gmail.com (Mbanya J. C.), sobngwieugene@yahoo.fr (Sobngwi E.), shmandengue@yahoo.fr (M. S. Honoré), etoundingoa@yahoo.fr (E. N. L. Serge) ${ }^{*}$ Corresponding author

\section{To cite this article:}

Ayina Ayina Clarisse Noel, Assomo Ndemba Peguy Brice, Mekoulou Ndongo Jerson, Bilog Nadine Carole, Ahmadou, Bindi Ngasse Josiane Gertrude, Etaga Noel Babayana, Temfemo Abdou, Mbanya Jean Claude, Sobngwi Eugène, Mandengue Samuel Honoré, Etoundi Ngoa Laurent Serge. Obesity and Risk of Comorbidity: Prevalence and Associated Factors in Children Aged 6 to 9 Years in Public and Private Schools in Douala-Cameroon. Central African Journal of Public Health. Vol. 6, No. 4, 2020, pp. 192-199.

doi: $10.11648 /$ j.cajph.20200604.12

Received: May 25, 2020; Accepted: June 10, 2020; Published: June 20, 2020

\begin{abstract}
Childhood obesity has unhealthy consequences, both in the short and long terms. Recently, a worrying increase in overweight and obesity in Sub-Saharan African children was reported. This study aims to determine the prevalence of obesity/overweight in public and private schools in children aged 6-9 years in the city of Douala, and identify the risk factors associated with obesity and comorbidities in this population. Parental health status; children's birth weight, breastfeeding duration, physical activity and settles way of life data were collected using a questionnaire, and correlated to obesity and related comorbidities indexes: waist circumference (WC), Waist to Height Ratio (WtHR) and body mass index (BMI). Obesity (9\%) and overweight (6.1\%) were found in children, mostly in private than in public schools $(13.82 \%$ versus $4.4 \%$ and $10.53 \%$ versus $1.9 \%$; $P<0.0001$ respectively). Parents overweight and diabetes histories, birth weight $(>4 \mathrm{~kg})$, breastfeeding duration ( $\leq 6$ months), having less than 6 breakfasts a week, watching television more than $2 \mathrm{hr} /$ day, sleeping less than $10 \mathrm{~h} /$ day and physical inactivity at school and home were significantly associated with obesity and related comorbidities in children ( $\mathrm{p}<0.05$ respectively). Overweight and obesity are a reality in these children, especially in those going to the private schools. Most of the factors associated are related to parents' and children's health history, but also to children's lifestyles that can be changed at home and at school.
\end{abstract}

Keywords: Obesity, Overweight, Childhood, School, Risk of Comorbidity, Birth Weight, Breastfeeding Duration, Skipping Breakfast, Sedentary Behaviours 


\section{Introduction}

Obesity is often defined as abnormal or excessive fat accumulation that may impair health [1]. Overweight and obesity represent a rapidly growing threat to the health of populations in an increasing number of countries [2]. This worrying trend appears to be affecting both developed and developing countries $[3,4]$.

Overweight and obesity result from the interaction of many factors, including genetic, metabolic, behavioral, and environmental influences. The rapidity with which obesity is increasing suggests that behavioral and environmental influences, rather than biological changes, have fueled the epidemic. Increasing energy consumption, decreasing energy expenditure, or a combination of both has led to a positive energy balance and a marked increase in weight in our society [5]. With improvement of economic situation in developing countries, increasing prevalence of obesity is seen in adults and particularly in children [6].

Childhood obesity and overweigh have negative health consequences, both in the short and long terms. Obese children are at a higher risk for later life obesity [7], diabetes $[7,8]$, cardiovascular diseases and their risk factors including high cholesterol levels, high blood pressure and abnormal glucose tolerance [7,9], cancers [7], childhood obesity has other side effects including difficulty of breathing [7] and asthma [10], psychosocial problems, fatty liver, orthopedicrelated problems, sleep apnea $[7,11]$ and premature death [7].

The main causes are increasing urbanization with less school-aged children walking or biking to school, nutrition transition with children consuming more calories per day than what's needed for the growth, physical activity and body function of a healthy weight teen, and reduced physical activity, children and adolescents spending on average more than six hours per day watching television, playing video games and using other types of media [12]. In addition, schools do not provide enough daily physical education or its equivalent (225 minutes per week for middle and high schools and 150 minutes per week for elementary school) [12]. These conditions lead to energy imbalance, too many children taking in more calories than they burn [12].

Between 1990 and 2010, overweight and obesity were estimated to cause 3.4 million deaths and $3.9 \%$ of life lost; about $6.7 \%$ of children were overweight (43 million), including 35 million in developing countries. [13]. Subsequently, it was noticed from 1980 to 2013 that the combined prevalence has increased by $27.5 \%$ for adults and $47.1 \%$ for children and the number of overweight and obese individuals increased from 857 million to 2.1 billion in the same period [14]. The worrying phenomenon then received an increased attention in developing countries, and a combined prevalence in children and adolescents between 1980- 2013 increased from 8 to $13 \%$ both for boys and girls. This trend was expected to reach $9.1 \%$ in 2020 representing approximately 60 million children [15].
Also, recent studies in Sub-Saharan Africa have indicated the worrying increase in overweight, obesity and associated factors in children $[16,17]$. Cameroon as a developing country is no exception to this epidemic phenomenon; in 2016, Non Communicable Diseases were estimated to account for $35 \%$ of all deaths [18]. Unfortunately, no studies have focused on childhood obesity at the national level. However, local studies raise awareness that overweightobesity in children is on the rise and can become a real public health problem $[19,20]$.

Hence, the aim of this study is to determine the prevalence of overweight and obesity in children aged 6 to 9 years attending public and private primary schools in the city of Douala in Cameroon, and indicate the related risk factors.

\section{Materials and Experiments}

\subsection{Study Population}

This was a cross-sectional study ran from November 2017 to February 2018 in public and private primary schools in the city of Douala, Cameroon. The study population consisted of children of both sexes (145 boys and 167 girls), aged 6-9 years. The Lorentz formula was used to calculate the minimum sample size with a prevalence of $2.9 \%$ reported by Choukem et al. in a cross-sectional study of obesity in children aged 3-13 years in relation to their socio-economic status in Douala [20]. The minimum size calculated was 312 participants (with $95 \%$ confidence level and a $5 \%$ margin of error, and a confidence level of 1.96). School boys and girls with infirmities, those with serious chronic illness, or ongoing or recent ( $<10$ days) acute illness, or those taking any current medication for weight loss and those with incomplete questionnaires were excluded from this study.

\subsection{Data Collection}

The participants received a questionnaire to be completed by their parents. The informations collected from this questionnaire were related to the risk factors for obesity, including birth weight, breastfeeding type and duration, parental obesity, hypertension and diabetes histories, physical activity (practice of physical activity at of school and at home, and the mean of transportation used to go to school), physical inactivity (time spent watching the television, sleep duration (the time of going to bed and waking up) and eating habits (number of breakfasts per week)). For each participant, anthropometric measurements took place between 9-12 hours in pupils dressed in light cloths. Weight was measured with a Tian Shan personmade weight scale (China) to the nearest $0.1 \mathrm{~kg}$, height with a calibrated stadiometer, waist circumference (WC) at midway between the lowest rib and the iliac crest to the nearest $0.5 \mathrm{~cm}$ and waist-to-height ratio (WHtR) as waist circumference divided by the height. Body mass index (BMI) was calculated using the Quetelet's formula as weight (in $\mathrm{kg}$ ) divided by height (in $\mathrm{m}^{2}$ ). 


\subsection{Definition of Obesity and the Risk of Comorbidities According to the Anthropometric Indices}

The weight status was assessed using BMI values, which were interpreted on the corpulence curves of French references of Rolland-Cachera et al. [21]; participants were categorized by areas of body by BMI, age and gender as follow: if $\mathrm{BMI}<3$ rd percentile, the child was underweight; when the 3rd percentile $<$ BMI $<97$ th percentile, the child was of normal build; if BMI $\geq 97$ th percentile, the child was overweight; when BMI was above the International Obesity Task Force of 30 threshold, the child was obese.

The risk of morbidity to obesity was determined using waist circumference (WC) and waist to height ratio (WHtR) values; children were at risk of developing comorbidities to obesity when $\mathrm{WHtR}>0.5$ [22], and/or $\mathrm{WC} \geq 97^{\text {th }}$ percentile using the LMS tables for waist circumference $Z$ scores obtained on North American children aged 5 to 19 [23].

\subsection{Statistical Analysis}

Data were coded, entered and analysed using the Statistical Package for Social Science (SPSS) version 16 (SPSS. Inc. Chicago. U.S.A.). The distribution pattern of the variables was checked. Normally distributed quantitative variables are expressed as mean with standard deviation (SD). Qualitative variables were expressed as percentages (\%). Student's t-test on unpaired series was used to compare clinical, behavioural and biological parameters between boys and girls, between public and private schools, or according to the presence or the absence of an obesity risk factor. Chi-square independence tests (bivariate statistics) and chi-square homogeneity test (univariate statistics) were used to compare unpaired proportions. Pearson correlation were performed to track association of anthropometric markers of obesity and comorbidity risk factors. Statistical tests are two tailed. A p value $<0.05$ was considered statistically significant.

\subsection{Ethics}

This study was approved by the Institutional Ethics Committee for Human Health Research of the University of Douala (CIS- Udo/835/03/2017/M), and by the Ministry of Public Health of Cameroon; and was conducted in accordance with the guidelines of the Helsinki Declaration of 1975, as revised in 2008. Also, research authorizations granted by school administration staffs. Written informed consent was obtained from all participants' parents. The participants were informed of the study objectives and modalities. All the data were collected anonymously and are confidential.

\section{Results}

The mean age of the population was $8 \pm 1$ years. Private schools pupils had significantly higher anthropometric characteristics compared to those in the public school (17.3 \pm 3.4 versus $16.1 \pm 2.1,58.4 \pm 6.7$ versus $54.6 \pm 4.4 ; \mathrm{P}<0.05$ for $\mathrm{WC}$ and $\mathrm{BMI}$ respectively).

\subsection{Prevalence of Obesity Using Obesity and Comorbidity Indexes}

A total prevalence of $6.1 \%$ and $9 \%$ respectively for obesity and overweight was found. No significant differences $(p=N S)$ were found between girls and boys, while overweight and obesity were more prevalent in private than in public schools ( $13.82 \%$ vs $4.4 \%$ and $10.53 \%$ vs $1.9 \%$; $<<0001$ respectively) (Table 1).

Table 1. Weight status and socio-demographic characteristics according to gender and type of school.

\begin{tabular}{|c|c|c|c|c|c|c|}
\hline & & & Gender & & Type of school & \\
\hline Variable & Category & Overall $(n=312)$ & Female $(n=167)$ & Male $(n=145)$ & Private $(n=152)$ & Public $(n=160)$ \\
\hline \multirow[t]{4}{*}{ Weight status $n(\%)$} & Underweight & $6(1.9)$ & $3(1.8)$ & $3(2.1)$ & $3(2.0)$ & $3(2.0)$ \\
\hline & Normal weight & $259(83.0)$ & $136(81.4)$ & $123(84.8)$ & $112(73.7)$ & $147(91.9)^{*}$ \\
\hline & Overweight & $28(9.0)$ & $16(9.6)$ & $12(8.3)$ & $21(13.8)$ & $7(4.4)^{*}$ \\
\hline & Obese & $19(6.1)$ & $12(7.2)$ & $7(4.8)$ & $16(10.5)$ & $3(1.9)^{*}$ \\
\hline \multirow[t]{2}{*}{ Birth weight $n(\%)$} & $\leq 4 \mathrm{Kg}$ & $294(94)$ & $137(46.6)$ & $157(53.4)^{*}$ & $147(50)$ & $147(50)$ \\
\hline & $>4 \mathrm{~kg}$ & $18(6)$ & $8(55.6)$ & $10(44.4)^{*}$ & $5(28)$ & $13(72)$ \\
\hline \multirow[t]{2}{*}{ Breastfeeding duration $n(\%)$} & $\leq 6$ months & $125(40)$ & $71(56.8)$ & $54(43.2)$ & $87(69.6)$ & $38(30.4)^{*}$ \\
\hline & $>6$ months & $187(60)$ & $96(51.3)$ & $91(48.7)$ & $65(34.8)$ & $122(65.2)^{*}$ \\
\hline \multirow[t]{2}{*}{ Mean of transport $n(\%)$} & Walk/Cycle & $170(54.5)$ & $96(56.5)$ & $74(43.5)$ & $39(22.9)$ & $131(77.1)^{*}$ \\
\hline & Motorcycle/Car & $142(45.5)$ & $71(50)$ & $71(50)$ & $113(79.6)$ & $29(20.4)^{*}$ \\
\hline \multirow[t]{2}{*}{ Television watch duration $n(\%)$} & $\leq 2 \mathrm{hr}$ & $279(89)$ & $152(54.4)$ & $127(45.6)$ & $122(43.7)$ & $157(56.3)^{*}$ \\
\hline & $>2 \mathrm{hr}$ & $33(11)$ & $15(45.5)$ & $18(54.5)$ & $30(91.0)$ & $3(9.0)^{*}$ \\
\hline \multirow[t]{2}{*}{ Sleep duration $n(\%)$} & $<10 \mathrm{hr}$ & $150(48.1)$ & $90(60.0)$ & $60(40.0)$ & $86(57.2)$ & $64(42.8)$ \\
\hline & $\geq 10 \mathrm{hr}$ & $162(51.9)$ & $85(52.7)$ & $77(47.3)$ & $77(47.7)$ & $85(52.3)$ \\
\hline \multirow[t]{2}{*}{ Physical activity at school $n(\%)$} & Yes & $281(90.0)$ & $146(52.0)$ & $135(48)$ & $124(44.1)$ & $157(55.9)^{*}$ \\
\hline & No & $31(10.0)$ & $21(67.7)$ & $10(32.3)$ & $28(90.0)$ & $3(10.0)^{*}$ \\
\hline
\end{tabular}

$n=$ number of participants; Data are presented as frequencies and percentage; $*=\mathrm{p}<0.05$ : significant difference between the categories (females versus males; private versus public schools) using chi square tests. Weight status was defined according to BMI. The Birth "Weight group $\leq 4 \mathrm{~kg}$ " includes children born with less than $2.5 \mathrm{~kg}(\mathrm{n}=10)$ because there was no statistical difference with children's' birth weight from 2.5 to $4 \mathrm{~kg}$.

The risk of comorbidity was more highly expressed with WHtR than with WC in boys (12.4\% vs $8.4 \%)$ and girls (10.2\% vs $5.5 \%)$, as well as in public $(7.5 \%$ vs $1 \%)$ and private $(15.1 \%$ vs $7.9 \%)$ schools. The risk of comorbidities was more present in private than in public school $(\mathrm{p}<0.05$ respectively using WC and WHtR) (Figure 1). 


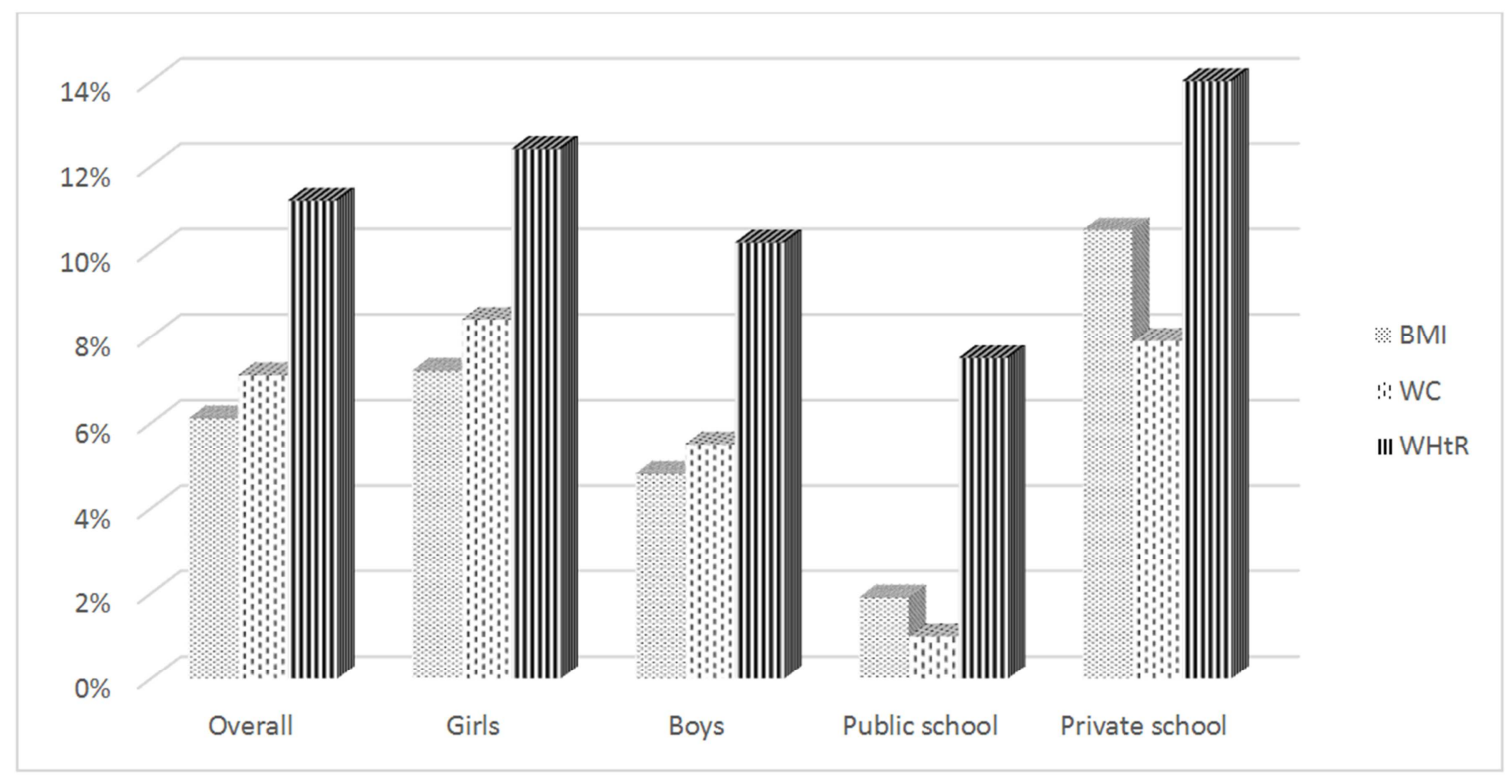

BMI: Body Mass Index; WC: Waist Circumference; WHtR: Waist-to-Height Ratio.

Figure 1. Prevalence of obesity by gender and type of school according to BMI, WC and WHtR.

\subsection{Relations Between Obesity Risk Factors and Obesity/Comorbidities Indexes}

In pupils whose father and/or mother had overweight/obesity history, BMI, WC and WHtR were significantly higher than in those with parents without obesity history $(p<0.0001$ respectively). BMI was significantly higher in pupils whose mother had diabetes history $(\mathrm{p}=0.0003)$, while WC was significantly higher in pupils whose father had diabetes history $(\mathrm{p}=0.02)$ compared to their counterparts whose parents did not report respective histories (Table 2). However, BMI was found significantly higher $(p=0.02)$ in pupils with high birth weight $(>4 \mathrm{~kg})$ than in those born with $4 \mathrm{~kg}$ or less, while $\mathrm{WC}$ was lower in pupils breastfed more than 6 months comparatively to those breastfed for less time $(\mathrm{p}=0.02)$ (Table 2$)$.

Table 2. Obesity indexes in relation with parental and personal health history of the children.

\begin{tabular}{|c|c|c|c|c|c|c|c|c|}
\hline Parents'/ Children's' health history & Category & $\mathbf{n}$ & BMI $\left(\mathrm{Kg} / \mathrm{m}^{2}\right)$ & P-value & WC (cm) & P-value & WHtR & P-value \\
\hline \multirow{2}{*}{ Father's overweight/obesity history } & Yes & 23 & $20.2 \pm 5.3$ & \multirow{2}{*}{$<0.0001$} & $64.7 \pm 9.2$ & \multirow{2}{*}{$<0.0001$} & $0.49 \pm 0.06$ & \multirow{2}{*}{$<0.0001$} \\
\hline & No & 289 & $16.4 \pm 2.4$ & & $56.0 \pm 5.2$ & & $0.44 \pm 0.03$ & \\
\hline \multirow{2}{*}{ Mother's overweight/obesity history } & Yes & 51 & $20.0 \pm 5.0$ & \multirow{2}{*}{$<0.0001$} & $62.1 \pm 9.0$ & \multirow{2}{*}{$<0.0001$} & $0.48 \pm 0.06$ & \multirow{2}{*}{$<0.0001$} \\
\hline & No & 261 & $16.1 \pm 2.0$ & & $55.4 \pm 5.0$ & & $0.44 \pm 0.03$ & \\
\hline \multirow{2}{*}{ Father's diabetes history } & Yes & 6 & $19.6 \pm 5.5$ & \multirow{2}{*}{0.11} & $64.7 \pm 8.06$ & \multirow{2}{*}{0.02} & $0.48 \pm 0.07$ & \multirow{2}{*}{0.11} \\
\hline & No & 306 & $16.6 \pm 3.0$ & & $56.3 \pm 6.0$ & & $0.44 \pm 0.04$ & \\
\hline \multirow{2}{*}{ Mother's diabetes history } & Yes & 6 & $22.3 \pm 5.0$ & \multirow{2}{*}{0.0003} & $62 \pm 13.0$ & \multirow{2}{*}{0.16} & $0.5 \pm 0.06$ & \multirow{2}{*}{0.2} \\
\hline & No & 306 & $17.0 \pm 2.8$ & & $56.4 \pm 6.0$ & & $0.4 \pm 0.04$ & \\
\hline \multirow{2}{*}{ Father's hypertension } & Yes & 7 & $18.2 \pm 54$ & \multirow{2}{*}{0.14} & $59.4 \pm 8.1$ & \multirow{2}{*}{0.18} & $0.46 \pm 0.05$ & \multirow{2}{*}{0.41} \\
\hline & No & 305 & $16.6 \pm 3$ & & $56.4 \pm 5.9$ & & $0.44 \pm 0.04$ & \\
\hline \multirow{2}{*}{ Mother's hypertension history } & Yes & 9 & $17.2 \pm 3.7$ & \multirow{2}{*}{0.56} & $56.9 \pm 7$ & \multirow{2}{*}{0.81} & $0.45 \pm 0.05$ & \multirow{2}{*}{0.48} \\
\hline & No & 303 & $16.7 \pm 2.9$ & & $56.4 \pm 5.9$ & & $0.44 \pm 0.04$ & \\
\hline \multirow{2}{*}{ Children's' birth weight } & $\leq 4 \mathrm{Kg}$ & 279 & $16.6 \pm 2.4$ & \multirow{2}{*}{0.02} & $56.26 \pm 6.5$ & \multirow{2}{*}{0.41} & $0.44 \pm 0.04$ & \multirow{2}{*}{0.10} \\
\hline & $>4 \mathrm{~kg}$ & 33 & $18.0 \pm 5.3$ & & $58.0 \pm 10.0$ & & $0.46 \pm 0.07$ & \\
\hline \multirow{2}{*}{ Children's' type of breastfeeding } & Maternal & 283 & $16.6 \pm 3.0$ & \multirow{2}{*}{0.29} & $56.3 \pm 5.8$ & \multirow{2}{*}{0.34} & $0.44 \pm 0.04$ & \multirow{2}{*}{0.59} \\
\hline & Artificial & 29 & $17.2 \pm 2.4$ & & $57.4 \pm 7.56$ & & $0.45 \pm 0.05$ & \\
\hline \multirow{2}{*}{ Children's' breastfeeding duration } & $\leq 6$ months & 125 & $17.1 \pm 3.3$ & \multirow{2}{*}{0.08} & $57.5 \pm 7.4$ & \multirow{2}{*}{0.02} & $0.44 \pm 0.06$ & 096 \\
\hline & $>6$ months & 187 & $16.4 \pm 2.9$ & & $55.7 \pm 5.2$ & & $0.44 \pm 0.04$ & 0.96 \\
\hline
\end{tabular}

$\mathrm{n}=$ number of participants; BMI: Body Mass Index; WC: Waist Circumference; WHtR: Waist-to-Height Ratio; Significance was set at p<0.05. The Birth "Weight group $\leq 4 \mathrm{~kg}$ " includes children born with less than $2.5 \mathrm{~kg}(\mathrm{n}=10)$ because there was no statistical difference with children's' birth weight from 2.5 to $4 \mathrm{~kg}$.

BMI, WC and WHtR were significantly lower in children walking to school than in those going to school by car and motorbike $(\mathrm{p}=0.0001)$; in those watching television less than 2 hours a day $(\mathrm{p}=0.0001)$; in those engaged in physical activities at home, and in those doing physical activity at school comparatively to their counterparts $(\mathrm{p}=0.0001)$. WC ( $\mathrm{p}=0.0001)$ and BMI ( $\mathrm{p}=0.001)$ were lower in children who slept at least 10 hours per day (Table 3 ). 
Table 3. Obesity indexes in relation with physical activity, sedentary behaviours and eating habits in children.

\begin{tabular}{|c|c|c|c|c|c|c|c|c|}
\hline Variable & Category & $\mathbf{N}$ & BMI $\left(\mathrm{Kg} / \mathrm{m}^{2}\right)$ & P-value & WC (cm) & P-value & WHtR & P-value \\
\hline \multirow{2}{*}{ Number of breakfasts per week } & $<6$ & 3 & $22.8 \pm 9.7$ & \multirow{2}{*}{0.0006} & $66.0 \pm 16.6$ & \multirow{2}{*}{0.007} & $0.5 \pm 0.1$ & \multirow{2}{*}{0.16} \\
\hline & $\geq 6$ & 309 & $16.5 \pm 2.3$ & & $55.5 \pm 4.5$ & & $0.4 \pm 0.03$ & \\
\hline \multirow{2}{*}{ Mean of transport/from to school } & Walking /Cycling & 170 & $16.0 \pm 2.0$ & \multirow{2}{*}{$<0.0001$} & $55.0 \pm 4.0$ & \multirow{2}{*}{$<0.0001$} & $0.44 \pm 0.03$ & \multirow{2}{*}{0.004} \\
\hline & Motorcycle /Car & 142 & $18.1 \pm 4.1$ & & $50.0 \pm 8.1$ & & $0.46 \pm 0.06$ & \\
\hline \multirow{2}{*}{ Physical activities at home } & Yes & 116 & $16.0 \pm 1.8$ & \multirow{2}{*}{0.0007} & $55.2 \pm 4.7$ & \multirow{2}{*}{0.05} & $0.4 \pm 0.04$ & \multirow{2}{*}{0.01} \\
\hline & No & 196 & $17.1 \pm 3.3$ & & $57.2 \pm 6.5$ & & $0.5 \pm 0.05$ & \\
\hline \multirow{2}{*}{ Physical activity at school } & Yes & 281 & $16.2 \pm 2.2$ & \multirow{2}{*}{$<0.0001$} & $55.5 \pm 4.7$ & \multirow{2}{*}{$<0.0001$} & $0.43 \pm 0.04$ & \multirow[t]{2}{*}{$<0.0001$} \\
\hline & No & 31 & $21.0 \pm 4.5$ & & $64.6 \pm 9.2$ & & $0.45 \pm 0.06$ & \\
\hline \multirow{2}{*}{ Television watching } & $\leq 2 \mathrm{hr}$ & 279 & 16. $3 \pm 2.4$ & \multirow{2}{*}{$<0.0001$} & $55.8 \pm 5.2$ & \multirow{2}{*}{$<0.0001$} & $0.43 \pm 0.03$ & \multirow{2}{*}{$<0.0001$} \\
\hline & $>2 \mathrm{hr}$ & 33 & $19.6 \pm 4.5$ & & $61.2 \pm 7.8$ & & $0.49 \pm 0.06$ & \\
\hline \multirow{2}{*}{ Sleeping } & $<10 \mathrm{hr}$ & 150 & $17.4 \pm 3.7$ & \multirow{2}{*}{0.001} & $58.1 \pm 6.8$ & \multirow{2}{*}{0.0001} & $0.44 \pm 0.05$ & \multirow[t]{2}{*}{0.17} \\
\hline & $\geq 10 \mathrm{hr}$ & 162 & $16.2 \pm 2.2$ & & $55.0 \pm 5.0$ & & $0.45 \pm 0.04$ & \\
\hline
\end{tabular}

$\mathrm{n}=$ number of participants; BMI=Body Mass Index; WC=Waist Circumference; WHtR=Waist-to-Height Ratio; Significance was set at $\mathrm{p}<0.05$.

BMI and WC where significantly higher in children who took breakfast less than 6 days a week $(\mathrm{p}<0.001$ respectively) (Table 3).

Significant correlations were observed between $\mathrm{WC}$ and BMI $(\mathrm{r}=0.750 ; \mathrm{p}<0.0001)$, also between WHtR and BMI $(\mathrm{r}=0.653 ; \mathrm{p}<0.0001)$ in overall population.

\section{Discussion}

The total prevalence of overweight and obesity was $15.1 \%$, precisely $9 \%$ for overweight and $6.1 \%$ for obesity. This prevalence of obesity is higher than that of $2.9 \%$ found among children aged 3-13 in the city of Douala in Cameroon [20]; and also than the $12.4 \%$ obtained among children aged $8-15$ in Cameroon urban children and adolescents in 2013 [19]. This difference in the prevalence's would result from the age group of their studies, which was wider than ours, including pre-adolescent children. Also, the different studies were actually conducted many years before ours. The prevalence of childhood overweight/obesity in the present study is higher than in some African developing countries in cross-sectional studies. More recent studies in Africa, Asia and Europe reported overweight and obesity prevalence's at least similar to or higher than those found in this study; precisely for overweight and obesity respectively $23.1 \%$ and $7.1 \%$ in Algeria [24] then $17.3 \%$ and $15.7 \%$ in Jordan [25], for obesity only $17.7 \%$ in Spain; $17.2 \%$ in Malta, $16.8 \%$ in Italy [26] and $20.6 \%$ in Iran [27].

In addition, the observation that children in private schools were more overweight and obese than those in the public school has been reported by some authors [25, 27-28], and could be explained by the socio-economic level which is higher in private schools' children's families when compared to that of children attending public schools. The authors concluded in their study that overweight/obesity were relatively common in sub-Saharan African children and that the prevalence was associated with High Socio Economic Status. They thought that this association may be mediated by sweet drink consumption, passive means of travel to school and not doing sport at school [20].

However, the risk of comorbidities (expressed by WHtR and WC) was more prevalent than that of obesity (expressed by BMI). Sharma et al. in 2015 reported on North American children and adolescents reference data, that WC and WHtR $\mathrm{Z}$ scores were useful measures of central adiposity in both clinical or research settings, that permit standardized comparisons across ages and genders and are more strongly associated with cardiometabolic comorbidities than BMI-Z. The authors also suggested that WHtR and WC may provide quantitative tools for the study of obesity and its complications [23]. Also, WHtR more highly expressed the risk of comorbidity than WC in the whole population, consistently with Ashwell et al. findings showing the superiority of WHtR over WC and BMI for detecting cardio metabolic risk factors in both sexes [29].

An increased WC and WHtR were correlated with BMI, and being overweight/obese was associated with a significant risk of obesity or comorbidities. These indexes thus not only constitute determinants for overweight and obesity, but also help in identification of central obesity and related adverse cardio metabolic conditions in overweight/obese children [22]. So, overweight/obese children had an important risk of obesity and related comorbidities. This result is consistent with those of many studies reporting strong relations between the increased risk and severity of obesity in childhood or in later life [30, 31, 32]. Also, children whose parents were overweight/obese had a significant risk of obesity and comorbidity compared to those whose parents had normal weight history. However, a history of diabetes in the mother has been significantly linked to the risk of obesity in the child, while the presence of diabetes in the father has been linked to the risk of central obesity and comorbidities in the child. These results are consistent with the strong linear relationship found between BMI / WC and risk of type 2 diabetes mellitus or obesity, obese individuals having almost 10 times the risk of diabetes, compared with their nonobese peers [30-34].

Children with a breastfeeding duration of more than 6 months had a lower WC $(\mathrm{p}=0.01)$ compared to children with a breastfeeding duration of $\leq 6$ months. Actually, studies in Africa and Europe reported that a long period of breastfeeding (more than 6 months) substantially reduced the risk of overweight and obesity in children, protecting these from overweight and obesity $[35,26]$. While children breastfed for a 
short period of time would absorb more calories [36] and bee at risk of obesity. A significant link between birth weight $(>4$ $\mathrm{kg}$ ) and obesity risk, precisely the increase in BMI has been observed in this study. Similar results have been reported by several studies for babies with more than $3.5 \mathrm{~kg}$ at birth $[36,37$, 38], showing that children with high birth weight were at high risk of overweight and obesity [26]. Also, children who had less than 6 breakfasts per week would be more likely to be obese than those who ate at least 6 breakfasts a week. Such association has been reported by Okada et al., who found a significant association between skipping breakfast in parents and children. According to them, children who skipped breakfast had significantly increased risk of childhood overweight/obesity [39]. The longer fasting period by skipping breakfast may increase the inflammation of peripheral blood cells, from higher postprandial insulin concentrations and increased fat oxidation [40].

Numerous studies suggest an inverse relationship between childhood overweight/obesity and physical activity [41-42]. Thus, the risk of obesity and overweight was observed in the means of locomotion used from and/or to school; students at risk being those who go to school by cars, motorcycles, decreasing the practice of physical activities as reported [43]. Non-practice of physical activity at home also presented a risk of an increase in BMI $(\mathrm{p}<0.0007)$ and WtHR $(\mathrm{p}<0.01)$, leading to an association between the prevalence of childhood obesity and a low or non-existent practice of physical activity [42]. The risk of obesity in this population was also associated with sedentary behaviours like spending more than 2 hours watching television, and short sleep duration. The number of hours spent watching television were significantly associated with overweight and childhood obesity [42, 44-45]. The time spent watching television replaces the time spent in physical activity, increases the energy intake and decreases the rate of resting metabolism. The link between sleep duration and obesity has been observed in some studies [46-47]. Physiologically, too short sleep interferes with the regulation of appetite and the resulting hormonal signals [48]. Lack of sleep leads to a disruption of the daytime cycle of growth hormones by increasing ghrelin and a parallel decrease in leptin. These two components will act at the lateral hypothalamus producing two neuropeptides orexines A and B stimulating arousal as well as food intake and increased hunger sensation [49].

\section{Limitations}

The main limitation of this study is its small sample size which hampered definitive inferences and drawing relevant conclusions. Thus, our findings need to be verified in further large population studies at a national level. However, the cross-sectional design of the study did not allow us to evaluate the impact of the others potential risk factors we have identified. Also, data were reported by parents, selfreporting bias is another potential limitation. To overcome this, we cross-checked the data with children's school files in case of doubt. Despite these shortcomings our study is one the very few to report on the relationship of Obesity risk factors with obesity outcomes among sub-Saharan Africans.

\section{Conclusion}

This study confirms the alarming and progressive nature of the prevalence of obesity and overweight in schools in Cameroon. The high prevalence found in this study indicate that obesity and the related risk of comorbidity are concerns to be managed urgently in primary schools, especially private schools in Cameroon. The risk of comorbidity was higher with WHtR than WC. Mother's diabetes history and children's birth weight ( $>4 \mathrm{~kg}$ ) were risk factors for obesity, while children with father's diabetes history and those breastfed less than six months were at risk for central obesity and the related risk of comorbidity. Parents' obesity history, going to school by car or motorcycle, short sleep duration $(<10 \mathrm{hr}$ a day), long-time of watching television ( $>2 \mathrm{hr}$ a day), skipping breakfasts and not being involved in physical activities neither at school nor at home were significant risk factors for obesity and the related risk of comorbidity in this young population. Considering these life style changes due to modernisation and industrialisation, it is urgent to put in place effective prevention and care strategies against obesity and its consequences both at home and at school for this young population.

\section{Competing Interests}

The authors declare that they have no conflict of interests.

\section{Acknowledgements}

The authors are grateful to all the volunteers and their parents who accepted to participate to this study; also all the school directors who authorised data collection.

\section{References}

[1] Garrow JS. Obesity and related diseases. London, Churchill Livingstone, 1988: 1-16.

[2] Popkin BM, Adair LS. Global nutrition transition and the pandemic of obesity in developing countries. ILSI. 2012; 70: $3-21$.

[3] WHO. Global strategy for diet, physical activity and health. http://www.who.int/topics/obesity/fr/, 2019. Accessed July 9, 2019.

[4] Finucane MM, Stevens GA, Cowan M, Danaei G et al. National, regional, and global trends in body-mass index since 1980: systematic analysis of health examination surveys and epidemiological studies with 960 country-years and 9.1 million participants. Lancet. 2011; 377 (9765): 557-567.

[5] Stein CJ and Colditz GA. Epidemic of Obesity. J Clin Endocrinol Metab, June 2004, 89 (6): 2522-2525. 
[6] Misra A. and Khurana L. Obesity and Metabolic syndrome in developing countries. J. Clin. Endocrinol. Metab. 2008; 93 (Suppl. 1), S9-S30.

[7] Chopra M, Galbraith S, Darnton-Hill I. A global response to a global problem: the epidemic of over nutrition. Bull World Heath Organ. 2002; 80 (12). pp. 952-958.

[8] The Writing Group for the SEARCH for Diabetes in Youth Study. "Incidence of diabetes in youth in the United States." Journal of the American Medical Association. 2007; 297: 2716-2724.

[9] Dietz W. "Health consequences of obesity in youth: Childhood predictors of adult disease." Pediatrics. 1998; 101: 518-525.

[10] Gilliland FD, Berhane K, Islam T, et al. "Obesity and the risk of newly diagnosed asthma in school-age children." American Journal of Epidemiology. 2003; 158 (5): 406-415.

[11] Kershnar A, Daniels S, Imperatore G, et al. "Lipid abnormalities are prevalent in youth with type 1 and type 2 diabetes: The SEARCH for Diabetes in Youth Study." The Journal of Pediatrics. 2006; 149 (3): 314-319.

[12] Wang YC, Gortmaker SL, Sobol AM et al. "Estimating the energy gap among U.S. children: A counterfactual approach." Pediatrics. 2006; 118: 1721-1733.

[13] Lim SS, Vos T, Flaxman AD et al. A comparative risk assessment of burden of disease and injury attributable to 67 risk factors and risk factor clusters in 21 regions, 1990-2010: A systematic analysis for the Global Burden of Disease Study 2010. Lancet. 2012; 380: 2224-60.

[14] Ng M, Fleming T, Robinson M, Thomson B et al. Global, regional, and national prevalence of overweight and obesity in children and adults during 1980-2013: a systematic analysis for the Global Burden of Disease Study 2013. Lancet. 2014; 384: 766-81.

[15] De Onis M, Blossner M, Borghi E. Global prevalence and trends of overweight and obesity among preschool children. Am J Clin Nutr, 2010; 92, 1257- 64.

[16] Muthuri SK, Francis CE, Wachira LJ et al. Evidence of an overweight/obesity transition among school-aged children and youth in Sub-Saharan Africa: a systematic review. PLoS One. 2014; 9 (3): e92846.

[17] Gebremedhin S. Prevalence and differentials of overweight and obesity in preschool children in Sub Saharan Africa. BMJ. 2015; 5: e009005. Doi: 10.1136/bmjopen-2015-009005.

[18] World Health Organization - Non communicable Diseases (NCD) Country Profiles, 2018.

[19] Wamba PC, Enyong J, Cianflone K. Prevalence of overweight, obesity, and thinness in Cameroon urban children and Adolescents. J Obes. 2013: 1-9.

[20] Choukem S, Kamdeu J, Leary D et al. Overweight and obesity in children aged 3-13 years in urban Cameron: a crosssectional study of prevalence and association with socioeconomic status. Obesity. 2017; 4: 7.

[21] Rolland-Cachera MF, Castetbon K, Arnault N et al. Body mass index in 7-9-y-old French children: frequency of obesity, overweight and thinness. Int J Obes. 2002; 26 (12): 1610 1616.
[22] Mokha JS, Srinivasan SR, Dasmahapatra P et al. Utility of waist-to-height ratio in assessing the status of central obesity and related cardiometabolic risk profile among normal weight and overweight/obese children: the Bogalusa Heart Study. BMC Pediatr. 2010; 10: 73.

[23] Sharma AK, Metzger DL, Daymont C et al. (2015). LMS tables for waist-circumference and waist-height ratio Z-scores in children aged 5-19 y in NHANES III: association with cardio-metabolic risks. International Pediatric Research Foundation. 2015; 78: 6.

[24] Allam O, Oulamara H, Agli, AN. Prévalence et facteurs de risque du surpoids chez des enfants scolarisés dans une ville de l'est algérien (Constantine). Antropo. 2016; 35: 91-102.

[25] Zayed AA, Beano AM, Haddadin FI et al. Prevalence of short stature, underweight, overweight, and obesity among school children in Jordan. BMC Public Health. 2016; 16 (1): 1040.

[26] Rito AI, Buoncristiano M, Spinellic A et al. Association between Characteristics at Birth, Breastfeeding and Obesity in 22 Countries: The WHO European Childhood Obesity Surveillance Initiative - COSI 2015/2017. Obes Facts. 2019; 12: 226-243.

[27] Abah SO, Aigbiremolen AO, Duru CB et al. Prevalence of overweight and obesity among students in private and public secondary schools in a peri-urban Nigerian town. J Biol, Agr Healthcare. 2012; 2 (11): 51-57.

[28] Kyallo F, Makokha A, Mwangi AM. Overweight and obesity among public and private primary school children in Nairobi, Kenya. Health. 2013; 5 (8): 85-90.

[29] Ashwell M, Gunn P, Gibson S. Waist-to-height ratio is a better screening tool than waist circumference and BMI for adult cardiometabolic risk factors. Systematic Review and metaanalysis. 2012; 13: 275-86.

[30] Svensson V, Jacobsson JA, Fredriksson R et al. Associations between severity of obesity in childhood and adolescence, obesity onset and parental BMI: a longitudinal cohort study. Int J Obes. 2011; 35: 46-52.

[31] Lake J, Power C, Cole TJ. Child to adult body mass index in the 1958 British birth cohort: associations with parental obesity. Arch Dis Child. 1997; 77: 376-38.

[32] Whitaker RC. Predicting Pre-schooler Obesity at Birth: The Role of Maternal Obesity in Early Pregnancy. Pediatrics. 2004; 114: 29-36.

[33] Colditz GA, Willett WC, Rotnitzky A et al. Weight gain as a risk factor for clinical diabetes mellitus in women. Ann Intern Med. 1995; 122: 481-486

[34] Chan JM, et al. Obesity, fat distribution, and weight gain as risk factors for clinical diabetes in men. Diabetes Care. 1994; 17: 961-969

[35] Bell S, Yew SSY, Devenish G et al. Duration of Breastfeeding, but Not Timing of SolidFood, Reduces the Risk of Overweight and Obesity in Children Aged 24 to 36 Months: Findings from an Australian Cohort Study. Int J Environ Res Public Health. 2018; 15, 599. Doi: 10.3390/ijerph15040599.

[36] Apfelbacher CJ, Loerbroks A, Cairns J et al. Predictors of overweight and obesity in five to seven-year-old children in Germany: Results from cross-sectional studies. BMC Public Health. 2008; 8, 171. 
[37] Faye J, Diop M, Badji L et al. Prevalence of Child and Teenage Obesity in Schools in Dakar. Bull Soc Pathol Exot. $2011 ; 104 ; 1: 49-52$.

[38] Vafa M, Moslehi N, Afshari S et al. Relationship between Breastfeeding and Obesity in Childhood. J Health Popul Nutr. 2012; 30 (3): 303-310

[39] Okada C, Tabuchi T, Iso H. Association between skipping breakfast in parents and children and childhood overweight/obesity among children: a nationwide 10.5-year prospective study in Japan. International Journal of Obesity. 2018; 42: 1724-1732.

[40] Nas A, Mirza N, Hagele F et al. Impact of breakfast skipping compared with dinner skipping on regulation of energy balance and metabolic risk. Ame J Clin Nutr. 2017; 105: $1351-61$.

[41] Tammelin T, Laitinen, J, Nayha S. Change in the level of physical activity from adolescence into adulthood and obesity at the age of 31 years. Int J Obes. 2004; 28: 775-782.

[42] Must A, Tybor DJ. Physical Activity and Sedentary Behaviour: A Review of Longitudinal Studies of Weight and Adiposity in Youth. Int J Obes. 2005, 29: 84-96.

[43] Gholami S, Rahmanian M, Ashkezari SJ et al. The Prevalence of Obesity and Overweight and Its Relevance to Transportation among Primary School Students: Yazd, Iran;
2015. Int J School Health. 2019 (In Press): e90365. doi: 10.5812/intjsh.90365.

[44] Jago R, Baranowski T, Baranowski JC et al. BMI from 3-6y of age is predicted by TV viewing and physical activity, not diet. Int J Obes. 2005; 29: 557-564.

[45] Gable S, Chang Y, Krull JL. Television Watching and Frequency of Family Meals Are Predictive of Overweight Onset and Persistence in a National Sample of School-Aged Children. J of Am Diet Assoc. 2007; 107: 53-54.

[46] Chaput JP, Brunet M, Tremblay A. Relationship between short sleeping hours and childhood overweight/obesity: results from the Quebec en Forme Project. Int J Obes. 2006; 30: 1080- 1085.

[47] Li L, Zhang S, Huang Y, Chen K. Sleep duration and obesity in children: A systematic review and meta-analysis of prospective cohort studies. J Paediatr Child Health. 2017; 53 (4): 378-385.

[48] Tremblay MS, Le Blanc AG, Kho ME et al. Systematic review of sedentary behaviour and health indicator in schoolaged children and youth. Inter J Behav Nutr Phys Act. 2011; 8: 98 .

[49] Hancox RJ and Poulton, R. Watching television is associated with childhood obesity: but is it clinically important? Int J Obes. 2006; 30: 171-175. 